\title{
FABRICANTE E REMENDADOR DE REDES DE PESCA: UM OLHAR A PARTIR DA ETNOGRAFIA VISUAL
}

\author{
Cristiano das Neves Bodart ${ }^{1}$ \\ Rochele Tenório Silva ${ }^{2}$
}

\section{Introdução}

\begin{abstract}
Toda imagem encarna um modo de ver. Inclusive a fotografia, pois as fotos não são, como se costuma supor, um mero registro mecânico. A cada vez que olhamos uma foto somos conscientes, mesmo que de maneira tênue, de que o fotógrafo escolheu aquela vista entre uma infinidade de outras possíveis (Berger, 2007: 6).
\end{abstract}

Partindo do pressuposto de Berger (2007), o presente artigo se propõe apresentar um estudo de campo exploratório-descritivo marcado pela descrição textual e pelo registro fotográfico, pois "de modos muito diversos ambos comunicam. Tanto as palavras e as frases que lemos em um texto, quanto as formas e as cores que vemos na imagem expressam algo sobre o mundo" (Novaes, 2008: 455).

Adotamos o uso de textos e imagens por acreditarmos que as imagens conduzirão os leitores a uma condição de interlocutores, para além da nossa maneira de enxergar o objeto em estudo. Dito de outra forma, embora as imagens estejam marcadas pelo "olhar dos fotógrafos", tais imagens permitem que os leitores tenham, em certa medida, suas próprias percepções, ou, nas palavras de Berger (2007), seu modo de ver.

O presente paper se aproxima bastante de um ensaio fotográfico, mas sem, contudo, distanciar-se da "tradicional narrativa etnográfica", atribuindo à fotografia um significado de conteúdo etnográfico, como sugerido por Bittencourt (1998).

\footnotetext{
O termo texto tem uma acepção clara - as palavras de um autor expressas em livro ou em qualquer outro escrito - e deriva do latim textum, entrelaçamento ou tecido. Certamente são muitos os tipos de texto: acadêmico, literário, poético, jornalístico, publicitário e assim por diante. No entanto, em todos se percebe a tessitura das palavras do autor, mesmo quando este não é nomeado. Tal não ocorre com a imagem. (Novaes, 2008: 455).
}

Ao buscar realizar um trabalho etnográfico reconhecemos que este caracteriza-se por estabelecer relações, selecionar informantes, transcrever textos etc., mas tendo a certeza de que a etnografia se define pelo esforço intelectual para entender e apreender

\footnotetext{
${ }^{1}$ Universidade de São Paulo, Brasil.

${ }^{2}$ Universidade de Vila Velha, Brasil.
} 
o objeto, o que permitirá a realização de uma descrição densa e interpretativa. (Geertz, 1989). A etnografia tem, ainda, por característica explorar a natureza de um fenômeno social particular, realizar entrevistas em profundidade, assim como a observação participante a fim de investigar os detalhes sob uma perspectiva microscópica (Rocha; Barros; Pereira, 2005), estando o pesquisador por dentro da realidade de um grupo e produzindo o saber a partir do ponto de vista do grupo em estudo.

Dito isto, o presente artigo é fruto de um ensaio etnográfico de uma atividade artesanal tradicional praticada por poucos indivíduos espalhado pelo litoral sul do Espírito Santo: os "fazedores e remendadores de redes artesanais" da região litorânea capixaba.

Esse trabalho caracteriza-se como "denunciativo" e "promotor". Por um lado realiza a denúncia do risco de desaparecimento desse profissional e de sua atividade, por outro, busca colaborar para a valorização de tal atividade, o que se deu inicialmente por meio de uma exposição fotográfica realizada em praça pública em uma das cidades do litoral sul capixaba, Piúma.

\title{
Base teórica e metodológica
}

\author{
As imagens foram feitas inicialmente para evocar \\ a aparência de algo ausente \\ John Berger
}

Você não fotografa com sua máquina. Você fotografa com toda sua cultura Sebastião Salgado

Pretende-se aqui realizar uma breve introdução do painel do estado da arte em torno do uso da fotografia nos estudos antropológicos. Embora não objetivamos nos aprofundar no uso metodológico da imagem, nos propomos realizar uma breve defesa e justificativa de seu uso, apontando que a fotografia, em auxílio ao texto etnográfico, pode revelar elementos aparentemente ausentes e não percebidos pelo pesquisador no momento que se passa a cena registrada (Berger, 2007: 6). Partimos da crença de que a evocação da memória é uma das maiores vocações da fotografia, podendo despertar paixões e/ou ser utilizada como meio de adquirir conhecimento, por isso caracteriza-se como um recurso metodológico importante e, em muitos casos, necessário. Somado a isso, temos notado que a imagem vem, paulatinamente, tomando centralidade no mundo 
contemporâneo, sendo objeto de interesse, sobretudo dentre os que não estão ligados diretamente ao fazer das Ciências Sociais.

Nenhum registro do passado pode oferecer um testemunho tão direto como as imagens, sendo mais ricas e precisas que a literatura (Berger, 2007), por esse motivo, ignorar o uso de registros fotográficos em descrições etnográficas não nos parece ser caminho metodológico frutífero. Vários antropólogos, ainda que tivessem percebido pouco o potencial de suas fotografias, se apropriaram delas para documentar e enriquecer seus registros etnográficos ${ }^{3}$. Não significa que as demais formas de registros devam ser ignoradas ou menos valorizadas, defendemos que existe uma complementaridade entre texto e imagem no processo de descrição etnográfica. A captura da imagem é feita pelo fotografo/etnólogo que traz consigo, em sua arte, sua forma de "ler o mundo", reconhecendo que as "imagens não reproduzem o real, elas o representam ou o reapresentam [...] Ela imita, mas sem ser idêntica àquilo que representa" (Novaes, 2008: 556 e 459).

A imagem, assim como o texto, é fruto de uma perspectiva de quem a registra/produz, nunca devendo ser tomada como o real, antes reconhecendo que ambas as descrições/representações "dar-se-ão a ler” a partir "do mundo interpretativo" do leitor (Chartieu, 1990).

A descrição etnográfica deve oferecer ao leitor múltiplas possibilidades de exploração do fenômeno cultural exposto, uma vez que "a cultura [...] é um contexto, algo dentro do qual eles podem ser descritos de forma inteligível - isto é, descritos com densidade" (Geertz, 1989: 24). O texto quando auxiliado por imagem pode proporcionar ao leitor condições de explorar a cultura em questão para além das percepções e perspectivas do descritas pelo pesquisador, em outras palavras, para além da representação que o pesquisador buscou expressar. As representações, sob a perspectiva de Roger Chartieu, grosso modo, são as leituras (no sentido de percepções/interpretações) do leitor de um dado fenômeno, o que é fruto das classificações e divisões organizadoras da apreensão do mundo social, sendo elas variáveis segundo as disposições dos grupos ou classes sociais (Chartieu, 1990) e fruto de suas relações. Dito isto, quanto mais elementos forem apresentados na descrição etnográfica, maior será a exploração interpretativa dos leitores. É necessário tomar consciência de que existe, por um lado, "o fazer-crer da vontade prescritiva dos autores"

\footnotetext{
${ }^{3}$ A esse respeito, leia "Lévi-Strauss: razão e sensibilidade" (1999), de Sylvia Caiuby Novaes, disponível em http://www.scielo.br/scielo.php?script=sci_arttext\&pid=S0034-77011999000100005.
} 
dos textos e, de outro, "as possíveis leituras rebeldes" dos mesmos textos provocadas por uma perspectiva de mundo diferente deste em relação àquele (Chartier, 1990; 1999). Desta forma, a ampliação de elementos a dar-se a ler na descrição etnográfica possibilita uma riqueza exploratória e compreensiva para além da capacidade e vontade dos autores.

De acordo com Boris Kossoy (2001), os registros fotográficos representam a visão de mundo do fotógrafo, isso independentemente do assunto proposto. $\mathrm{O}$ mesmo ocorre com o texto, porém sendo mais provável a ocorrência de registros não percebidos pelo etnólogo quando o texto é acompanhado por imagens, enriquecendo as possibilidades de percepção do leitor. As "imagens favorecem, mais do que o texto, a introspecção, a memória, a identificação, uma mistura de pensamento e emoção" (Novaes, 2008: 465). Para Kossoy,

Uma única imagem contém em si um inventário de informações acerca de um determinado momento passado, ela sintetiza no documento um fragmento do real visível, destacando-o do contínuo da vida. Monumentos históricos, vestuários, posses e aparências dos personagens e estão ali esperando interpretações. (Kossoy, 2001: 101).

É justamente devido a tal inventário rico de informações que o etnólogo pode - e deve - recorrer ao uso da imagem fotográfica no processo de descrição do fenômeno cultural estudado. Além de poder apresentar sua leitura, maximiza as possibilidades do leitor em realizar outras leituras e descobertas, em síntese, ser analista e etnólogo, ainda que durante a leitura e reflexão do texto e das imagens. Como destacou Bittencourt (1998), os recursos imagéticos acabam por transcender os limites das descrições textuais, porém não as substituem.

Embora o uso de imagens na Antropologia tivesse sido costumeiramente utilizado para representar o contexto estudado (Bittencourt, 1998; Novaes, 2012), apenas recentemente, sobretudo nos anos de 1980 e 1990, com o desenvolvimento da "Antropologia da Imagem", que passou a ter significativa centralidade nos estudos etnográficos. Para Clarice Peixoto (1998), o uso da fotografia nos estudos antropológicos veio para ampliar os limites desta disciplina. Para Bittencourt (1998), a fotografia colabora com a Antropologia na tentativa de conseguir retratar as experiências do mundo de uma forma mais sensível e detalhada como as expressões de sentimentos, as comunicações não verbais, os sistemas de atitudes, etc. Por esse motivo, 
essa autora defende que na pesquisa de campo o pesquisador não deve ater-se apenas à descrição textual e sua análise, mas também se apropriar das contribuições dos recursos imagéticos.

Podemos finalizar essa seção mencionando as potencialidades da associação entre imagem e texto destacada por Sylvia Caiuby Novaes (2008): fotografias e textos nos emocionam pelo que transmitem; a imagem não diz o que é, mas por meio da complementaridade do texto pode expressar mais do que palavras; a imagem associada ao texto tem maior poder de despertar o sentimento de realidade; a imagem tem como único tempo o presente, que, apoiado pela escrita, é capaz de eternizar ou "reviver os mortos". Diante disso tudo não podemos perder de vista que "o engajamento com a imagem propicia a realidade representada, jamais a realidade da representação" (Novaes, 2008: 461).

\section{Base metodológica e procedimentos}

A inserção em campo teve início a partir de diversas conversas informais com pescadores da região que se utilizam dos trabalhos dos artesãos fabricantes e remendadores de redes de pesca. O objetivo inicial foi compreender o contexto socioeconômico que os envolve. Em todas as etapas da pesquisa tomamos o diário de campo como instrumento de registros de nossas impressões, procurando

tirar a capa de membro de uma classe ou grupo social específico para poder - como o etnólogo - estranhar alguma regra social familiar e assim descobrir (ou recolocar, como fazem as crianças quando perguntam os 'porquês') o exótico no que está petrificado dentro de nós pela reificação e pelos mecanismos de legitimação. (Da Matta, 1978: 29).

Posteriormente, buscamos encontrar esses artesãos ao longo do litoral sul capixaba, mais precisamente nos municípios de Anchieta, Piúma e Itapemirim. Encontrados, de forma aleatória foram realizadas entrevistas semiestruturadas a dez (10) artesãos, entre fabricadores e remendadores de rede de pesca. As entrevistas ocorreram sempre no local e no momento em que exerciam suas atividades, algumas vezes não sendo possível a gravação em áudio, devido os entrevistados não se sentirem à vontade. Objetivamos nas entrevistas "tomar nota" e traduzirmos o universo cultural distinto (Mauss, 1966) dos artesões, buscando compreender seus significados/sentidos aferidos por esses profissionais a sua arte e ferramentas, para assim, como orientou Velho (1978: 
127), "pôr-se no lugar do outro". Esse contato direto é importante por reconhecermos que "existe dissenso em vários níveis, a possibilidade de conflito é permanente e a realidade está sempre sendo negociada entre atores que apresentam interesses divergentes" (Velho, 1978: 41) e cabe ao pesquisador compreender e descrever. É importante reconhecermos a existência no olhar do pesquisador, ainda que eles sejam indesejáveis (Da Matta, 1978: 31), para assim buscarmos,

[...] relativizar as noções de distância e objetividade, [e] se de um lado nos torna mais modestos quanto à construção do nosso conhecimento em geral, por outro lado, permite-nos observar o familiar e estudá-lo sem paranoias sobre a possibilidade de resultados imparciais, neutros". (Velho, 1978: 43).

Após nossa presença por alguns dias e realizadas as entrevistas solicitamos que nos deixassem realizar alguns registros fotográficos de suas atividades. Nesse momento, buscamos interferir o quanto menos nas práticas artesãs. Partimos da orientação de Clarice Peixoto (1998), que, ao indicar que o registro de imagens deve ser entendido como uma (re)apresentação do real, mas que podem acabar expressando abstrações que dificultem a compreensão do cenário. Por esse motivo, a autora indica que faz-se prudente a realização de um "roteiro" prévio, a fim de evitar fotografias abstratas e incompreensíveis pelos leitores, o que fizemos.

Em alguns casos só foi possível realizar dois contatos com os entrevistados, ainda que durante algumas horas, isso devido à dificuldade do diálogo ${ }^{4}$. Nesses casos, no primeiro contato com os artesãos conversamos sobre seu cotidiano e, posteriormente, fizemos algumas fotografias e, em um segundo momento, levamos algumas fotografias impressas em tamanho 30x40 cm para introduzir o tema da pesquisa, ganhar confiança e facilitar o caminho para as entrevistas semiestruturadas. Como bem descreveu Sylvia Caiuby Novaes,

Qualquer pesquisador sabe o quanto é difícil introduzir o tema que lhe interessa pesquisar a seus interlocutores. As fotografias são neste sentido estratégicas: o tema "não cai do céu", ele é motivado pelas fotos, que permitem ao pesquisador introduzir questões, esclarecer dúvidas, colher ricos depoimentos, acompanhar as discussões que as fotos suscitam entre as pessoas. (Novaes, 2012: 17).

\footnotetext{
${ }^{4} \mathrm{O}$ contato com artesãos de Itapemirim foi mais difícil e marcado por desconfianças, o que foi rompido por meio de conversas longas descontraídas sobre o cotidiano dos entrevistados, ainda que as narrativas não fossem marcadas por alegrias e conquistas, sobretudo materiais.
} 
Quanto ao cuidado com a ação de fotografar, Novaes alerta que,

Quando o pesquisador consegue estabelecer relações de confiança entre aqueles que pesquisa e se o pesquisador tem, além disso, uma sensibilidade treinada, saberá quando e o que pode fotografar. (Novaes, 2012: 17).

Considerando essas indicações, buscamos conhecer primeiramente quem são os artesãos, para posteriormente buscar compreender sua atividade e, por fim, realizarmos o presente relato etnográfico. Perguntamos como gostariam de ser fotografados. A maioria deles pediu que evitássemos o registro de suas faces.

Após fazermos centenas de registros fotográficos, buscamos selecionar aquelas que melhor representassem a arte de remendar redes $^{5}$, ora optando por usar imagens com enquadramentos mais amplos, registrando parte significativa do ambiente, ora com enquadramento mais fechado, cujo objetivo foi focalizar na atividade. Cremos que a somatória "texto mais imagens" proporcionará ao leitor uma interpretação mais rica. As fotografias são apresentadas nesse artigo de forma a integrar um conjunto uno, tanto entre imagem e texto, como as sequências de imagens selecionadas e expostas desse trabalho, pois reconhecemos que "[...] o sentido de uma imagem depende daquelas que a precedem, e sua sucessão cria uma realidade nova, que não é a simples soma dos elementos empregados". (Merleau-Ponty, 1983: 111).

A atividade de fabricador e remendador de rede envolve técnica e atenção, sobretudo no "fazer pano", que é a produção das malhas que compõem a rede. As etapas da produção ou costura das redes possuem elementos materiais e simbólicos estranhos aos outsiders, mas socialmente reconhecidos por aqueles que estão envolvidos nessa arte. Os achados da pesquisa são apresentados a seguir e foram organizados em formato de uma exposição fotográfica realizada em uma praça pública utilizada por esses profissionais e pescadores de uma das $\operatorname{cidades}^{6}$ onde se deu a pesquisa.

\footnotetext{
${ }^{5}$ Não conseguimos registrar a fabricação de rede devido ao fato de termos notícias apenas de um profissional que ainda as fazem artesanalmente, porém há meses não é contratado para tal tarefa, apenas para realizar o remendo das redes produzidas industrialmente.

${ }^{6}$ Optamos por realizar na cidade de Piúma por se localizar onde há o maior risco de desaparecimento desse ofício.
} 


\section{O fabricante e remendador de rede de pesca artesanal}

O perfil do artesão fabricante e remendador de rede é bastante homogêneo nos municípios de Anchieta e Piúma. Em sua grande maioria são homens ${ }^{7}$, ex-pescadores que abriram mão de suas atividades tradicionais para dedicar-se a esse novo trabalho; todos, com rendimento médio mensal de cerca de pouco mais de mil reais ( $\mathrm{R} \$ 1.000,00)$, recebendo, por dia trabalhado, entre 45 a 60 reais. Todos os artesãos identificados nesses dois municípios trabalham nessa atividade há mais de 20 anos, tendo aprendido essa arte quando ainda eram pescadores. No município de Itapemirim, mais ao sul, no pequeno vilarejo denominado Pontal da Barra do Itapemirim $^{8}$, encontramos um povoado de pescadores descendentes de índios tupiniquins, onde quem realiza a atividade de remendar redes são majoritariamente as mulheres, sobretudo as mulheres esposas de pescadores, com idade entre 28 e 40 anos. Vidas marcadas por um conflito recente com o Instituto Brasileiro do Meio Ambiente e dos Recursos Naturais Renováveis (IBAMA), órgão que proibiu o formato de pesca tradicional naquele vilarejo.

Em entrevistas realizadas com os artesãos de Anchieta e Piúma notamos que o cansaço causado pela pescaria em alto mar, o perigo dessa atividade e alguns problemas de saúdes causadas por ela, são os principais responsáveis pela introdução desses artesãos na arte de fabricar e remendar redes. Nota-se que a falta de qualificação profissional dos ex-pescadores e a falta de oportunidades de trabalho no litoral sul capixaba nas décadas de 1960, 1970 e 1980 foram, juntamente com os problemas já mencionados, corresponsáveis pela escolha da nova profissão. Outro fator igualmente importante é a continuidade desses indivíduos ao círculo de amigos dos pescadores.

No Pontal da Barra do Itapemirim as mulheres, esposas de pescadores, têm na atividade de remendo de rede um complemento de suas rendas familiares. Como a maioria dos pescadores daquele vilarejo trabalham para terceiros como "marujos" e não possuem redes e/ou barco, elas prestam o serviço aos pescadores das cidades Barra do

\footnotetext{
${ }^{7}$ Nesses dois municípios tivemos notícia apenas de duas mulheres, uma ainda em atividade, a qual foi entrevistada.

${ }^{8}$ Esse vilarejo possui cerca de 500 moradores oriundo do crescimento vegetativo dos primeiros moradores que moravam às margens do Rio Itapemirim. Trata-se de uma ocupação desordenada e ilegal de terreno de marinha (local onde havia vegetação de mangue e restinga).
} 
Itapemirim (sede do vilarejo) e Marataízes, cidade próxima localizada pouco mais ao sul. Esse fenômeno se evidencia, a título de ilustração, no seguinte depoimento:

[...] não sei se quando meu marido chegar do mar vai ter feito uma boa pescaria e trazer dinheiro pra dentro de casa. Três semanas que ele fica pra lá, dá para eu ganhar algum dinheiro remendando rede para ajudar em casa e comparar as coisas para as crianças (sic).

Enquanto que em Anchieta e Piúma, o ofício de remendar rede é tipicamente masculino, já no vilarejo Pontal da Barra do Itapemirim o trabalho é predominantemente realizado pelas mulheres. Diferencia-se o valor pago pela mão de obra das mulheres em relação ao que se paga aos homens. Enquanto que em Anchieta e Piúma um artesão recebe cerca de 60 reais, a única mulher que realiza o ofício recebe 45 reais. As "mulheres do Pontal" (são assim comumente chamadas as mulheres do Pontal Barra do Itapemirim) recebem ainda menos pelos seus serviços de artesã, cerca de 25 reais por rede remendada, tarefa que leva todo o dia. O que há em comum entre todos é a técnica e o iminente risco de desaparecimento.

\section{$O$ risco de desaparecimento}

É sabido que a pesca artesanal está em constante decadência no litoral sul do estado do Espírito Santo, bastando para isso ver a redução gradativa de barcos de pesca e de barcos que saem para o mar com menos marujos do que o desejado e necessário. A partir de entrevistas realizadas a alguns pescadores da região levantamos a hipótese de que tal decadência parece se dar por três fatores: i) redução do pescado na região; ii) a concorrência com a "indústria da pesca", marcada por barcos maiores e dotados de tecnologias cada vez mais sofisticadas; e iii) dificuldade na manutenção da mão de obra, já que a região nos últimos anos passou a apresentar outras opções de ocupação devido ao desenvolvimento urbano e industrial e ao fato de que os jovens menos escolarizados (rejeitados pela indústria e o comércio) têm sido amplamente vitimados pelo consumo de drogas, sobretudo pelo crack.

Nota-se que, no caso do litoral sul capixaba, a pesca vem, paulatinamente, perdendo seus "encantos" e a reposição de pescadores parece não ocorrer. Ligado diretamente a pesca há uma atividade profissional, também artesanal, que vem correndo um risco ainda maior de deixar de existir nos próximos anos: a fabricação e remendo de 
redes artesanais de pesca. Tal atividade que era, quase sempre, a opção dos pescadores ao deixarem a pesca encontra-se em franco declínio por três motivos aparentes correlatos aos problemas enfrentados pela pesca artesanal: i) a redução do número de pescadores; ii) o surgimento e desenvolvimento de redes de pesca produzidas industrialmente, as quais são vendidas à preços mais baratos e o pescador ao optar por comprá-las nas lojas sua obtenção é imediata; e iii) dificuldade de reposição de mão de obra. No caso das "mulheres do Pontal", há ainda um problema recente, mas que amplia fortemente esse risco de desaparecimento: a proibição do uso das redes tradicionais por parte do IBAMA; esta sendo a rede que mais demandam a atividade de remendo. Hoje elas remendam tais redes escondidas em seus quintais, assim como os pescadores as utilizam de forma clandestina.

Até os anos de 1990 muitos pescadores, após anos de experiência com a atividade pesqueira, optavam por abandonar o mar e encontraram na atividade artesanal de fabricação e remendo de redes de pesca uma forma de manter seu sustento. Eram pescadores que por algum motivo "[...] amavam mais a rede do que o mar", dedicandose a produção e conserto de redes de pesca. Atualmente existem alguns poucos profissionais que “fabricam, remendam e 'entralham' redes de pesca, evidenciando o risco de desaparecimento da atividade e com ela parte da cultura de cidades historicamente pesqueiras, tais como Anchieta, Piúma, Itapemirim e Marataízes.

Para exemplificar a gravidade, em nosso levantamento com os pescadores notamos a existência de apenas um profissional no município de Piúma que ainda trabalha fabricando rede de pesca e sete profissionais que trabalham apenas com "remendo" (costura) e "encala" (fixação das cordas, boias e chumbos nos panos das redes). A produção industrial de "panos de rede" (malhas) tem tido uma concorrência que os antigos fazedores de rede não conseguiram vencer, restando por aquilo que as fábricas ainda não fazem, que é a "encala", os "remendos" pequenos e a fixação de "tacões" (pedaços de redes que são utilizados como emendas para cobrir buracos grandes).

Há claramente o risco de desaparecimento dessa atividade nos próximos anos, sem, contudo, grande parte da população mais jovem ter conhecido essa atividade que faz parte de suas raízes culturais.

Hoje é difícil ver esse artesão realizando seu ofício. Isso pela escassez desse profissional e pelo fato de que a realização de suas tarefas, que se dava nos espaços 
públicos, está cada vez mais se confinando em quintais murados e varandas de suas residências ou do pescador contratante, dono da rede, como se observa na imagem 1.

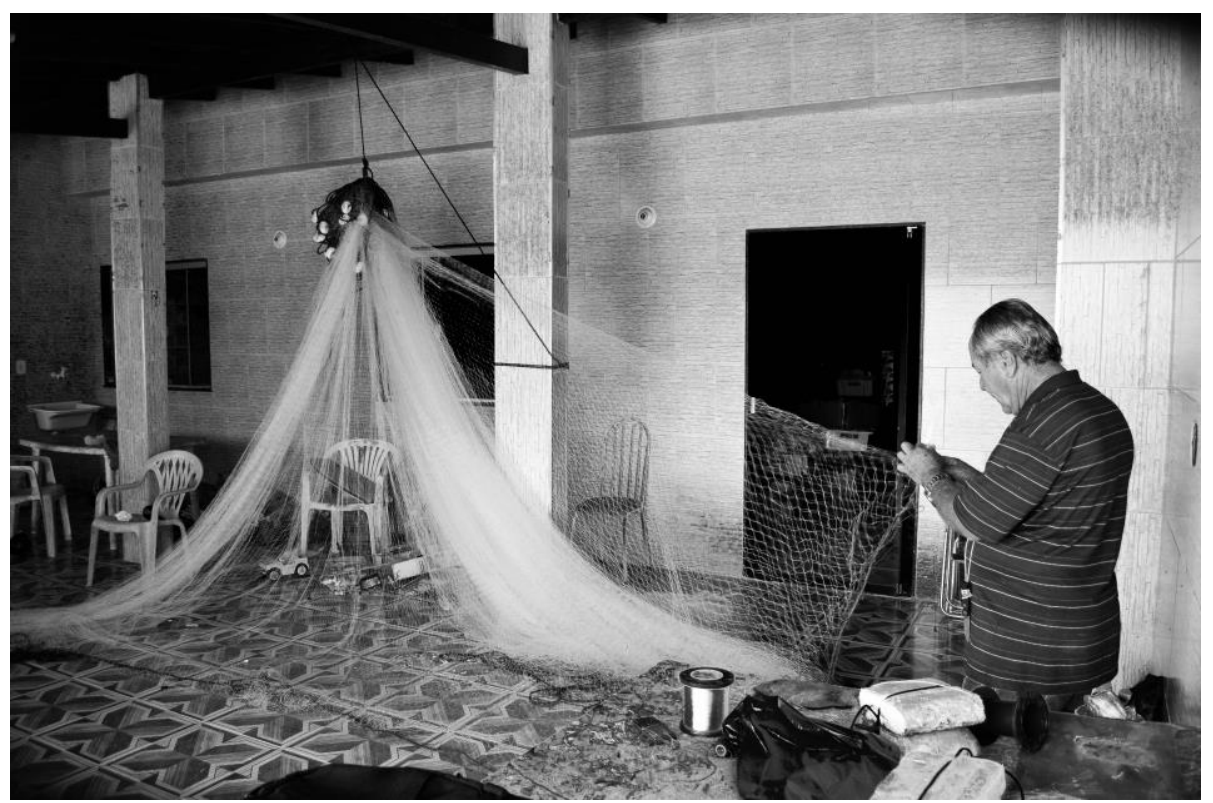

Imagem 1 - O ofício confinado. Fotografia: Cristiano das Neves Bodart

Com o crescimento urbano, os espaços públicos, antes utilizados, tais como praças e ruas, deixaram de ter a tranquilidade necessária para a concentração do artesão na realização de seu ofício. Por esse motivo, o artesão vem se confinando em espaços fechados e privados, fazendo com que essa atividade não seja mais vivenciada pela sociedade e, consequentemente, quase caindo no esquecimento. A partir de um olhar atento a imagem 1, vemos que há uma sobreposição do uso do espaço. Nota-se que o mesmo lugar em que é realizado o remendo de rede, é o lugar de lazer da família, sendo percebido a existência de várias cadeiras e brinquedos em meio a rede que ocupa quase todo o espaço físico da varanda. De acordo com esses profissionais, deixar os espaços públicos reduziu a comunicação entre os profissionais desse ofício. Antes, uma árvore de uma praça era compartilhada por dois ou mais remendadores de rede o que facilitava também a divisão de "empreitadas"9 entre eles. A amizade, embora ainda perdure, tornou-se baseada em relações sociais anteriores devido a escassez de encontro entre eles. Quando o encontro acontece, quase sempre a assunto são os “causos passados" (experiências curiosas e engraçadas vivenciadas por eles no passado). Nota-se que as

\footnotetext{
${ }^{9}$ Quando um artesão recebia nova proposta de remendar outra rede, mas estava ocupado trabalhando em outra, ele indicava prontamente outro remendador, quase sempre que trabalhava no mesmo espaço público.
} 
relações sociais sofreram, por redução da comunicação, mudanças substantivas, tornando-se cada vez mais impessoal e baseada apenas em um passado em comum.

No caso das "mulheres do Pontal" o risco de desaparecimento foi acelerado recentemente devido à proibição do uso, a partir de 2007, de um tipo de rede que era tradicional no vilarejo na pesca de lagosta: a caçoeira.

A escassez de redes para remendar afetou a rotina anterior, marcada por uma participação maior da mulher na renda familiar e com isso na autonomia da mulher, sobretudo sobre os filhos e quando seus esposos estão em alto mar.

A caçoeira é uma rede de pesca de lagosta considerada predatória pelo IBAMA e proibida em todo o Brasil ${ }^{10}$. Ela se diferencia das demais pelo tipo de nylon usado em sua fabricação, chamado de nylon mole (multifilamento), enquanto o outro tipo de rede é feita de nylon duro ou nylon de plástico (monofilamento). Os pescadores preferem tal rede por ter o nylon mais resistente e pelo fato de rasgarem bem menos que a rede de nylon de plástico. Segundo um dos pescadores pesquisados "essa rede dura cerca de 15 anos ou mais, bastando remendar de vez em quando. Já a rede de plástico rasga muito e não vale a pena remendar, pois o pano é vendido nas lojas por 150 reais". Após essa proibição o número de redes para remendar caiu drasticamente, levando muitas mulheres a buscarem outras atividades.

Até 2009 havia na região sul do estado do Espírito Santo, mais precisamente no município de Piúma, uma escola de Ensino Fundamental ( $5^{\circ}$ ao $8^{\circ}$ ano) voltada para a Pesca, conhecida como "Escola de Pesca". Essa escola, fundada pelo Governo Federal, em 1986, e posteriormente municipalizada, tinha por objetivo ensinar a arte da pesca e da fabricação de redes e barcos aos alunos da região (Anchieta, Piúma, Itapemirim e Marataízes), além de ofertar, concomitantemente, o ensino regular. Ainda que muitos alunos tivessem passado por aquela escola, não temos registros de algum que tivesse passado a dedicar-se a fabricação e remendo de redes. Em 2010, a "Escola de Pesca" deu lugar ao Instituto Tecnológico Federal do Espírito Santo (IFES), campus Piúma, e embora o primeiro curso superior ali estabelecido fosse Engenharia de Pesca, a arte de fabricar e remendar redes não foi mais praticada por falta de profissional que possuísse tal habilidade e escolaridade mínima para a sua contratação. Ainda assim, resistem

\footnotetext{
${ }^{10}$ Por meio da Lei $\mathrm{n}^{\mathrm{o}} 11.524$, de 24 de setembro de 2007 os pescadores receberam indenizações para que entregassem suas redes caçoeiras de pesca de lagosta.
} 
alguns poucos profissionais a manterem viva essa atividade tradicional, a qual relataremos na seção seguinte.

\section{Registros textuais e imagéticos do ofício de fabricante e remendador de rede de pesca artesanal}

Para a realização da arte de fabricar e remendar redes é necessário habilidade, atenção, rapidez e uma boa visão.

Antes de nos atermos ao ofício em questão, gostaríamos de descrever a rede (do tipo mais comum) para o entendimento posterior das descrições textuais e as representações imagéticas.

A rede é composta basicamente por quatro partes: a boia; o chumbo, a encala e o pano (ver imagem 2). O que é chamado de boia não é exatamente a boia como a conhecemos, mas a corda onde esta fica presa. A boia é composta por uma corda de multifilamento, do comprimento da rede, e isopores presos espaçados entre si, os quais servem de boias (algumas boias são produzidas em poliuretano) Essa parte é responsável por manter a rede sob a água na vertical. Trata-se da parte superior da rede.

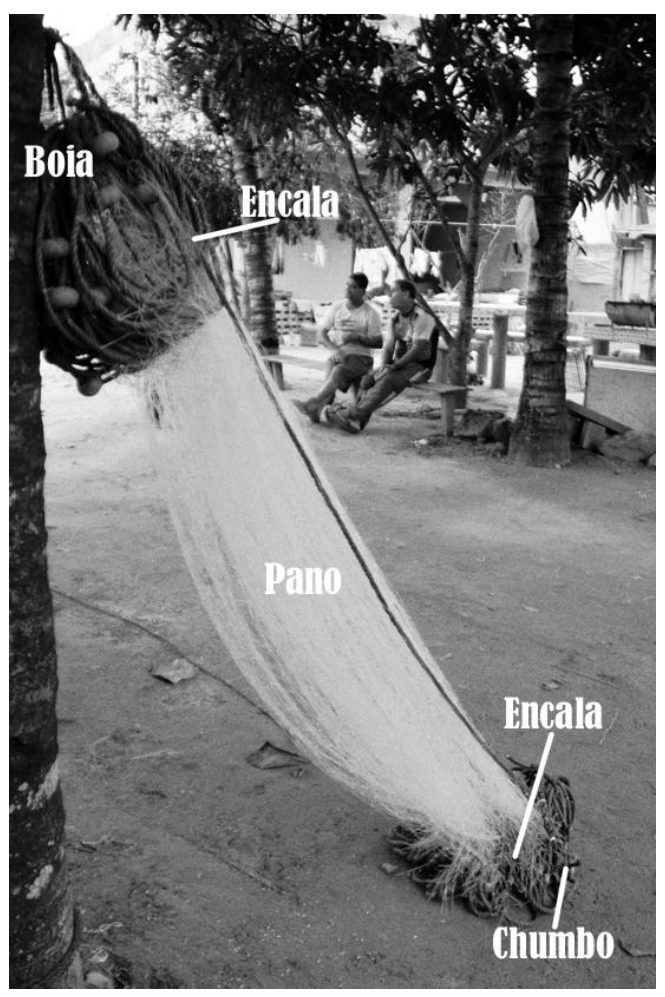

Imagem 2 - Rede de pesca. Fotografia: Rochele Tenório Silva. 
O chumbo é a parte inferior, composta também por uma corda de multifilamento do comprimento da rede. Essa corda é repleta de chumbos espaçados entre si. Seu objetivo é manter a parte debaixo da rede no fundo do mar. A encala é composta pelo nylon de multifilamento, da espessura da rede, que prende o pano as cordas do chumbo e da boia. Algumas redes têm seus panos produzidos com esse nylon (que não as caçoeiras). O que chamam de pano é o corpo da rede feita de nylon em formato de malhas, estas variando de acordo com o tamanho de peixe que será pescado. Tanto a corda do chumbo, quanto a corda do baio, são chamadas de "tralha", daí o nome "entralhar", atividade de colocar o chumbo e a boia no pano da rede no momento de seu fabrico.

As ferramentas utilizadas no ofício de fabricação e remendo de rede são: uma faca pequena e amolada (quase sempre pendurada no pescoço por uma corda em forma de cordão); uma pedra de limar; agulhas de remendar rede de pesca com "nylon duro" e "nylon mole". Nota-se nas imagens 3 e 4 as facas bastante desgastadas, resultado de um trabalho constante e da exigência de esta ferramenta está sendo sempre amolada.

Imagem 3 e 4 - Mão e ferramentas do ofício em acão. Fotografia: Cristiano das Neves Bodart.
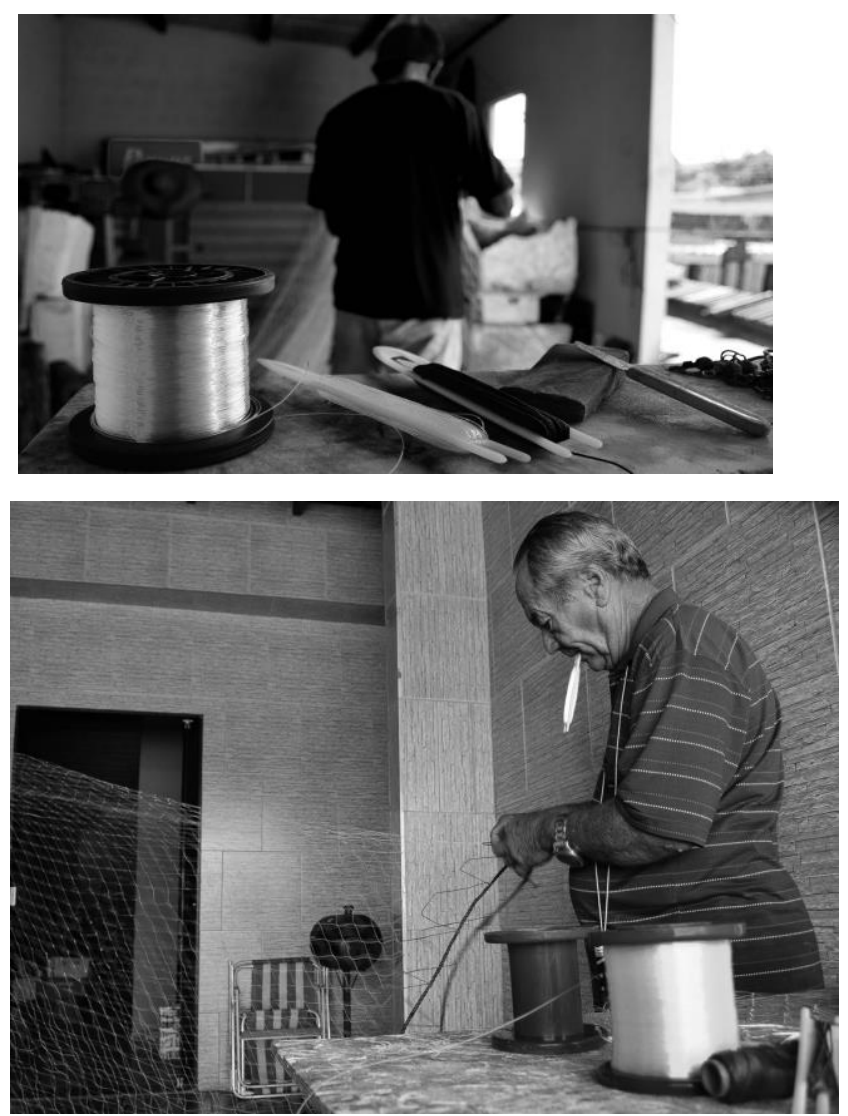
O artesão utiliza-se de suas duas ligeiras mãos, recorrendo muitas vezes ao uso da boca para segurar a agulha de costura (ver imagem 4). A faca pendurada em uma espécie de cordão contribui para que as mãos fiquem livres enquanto uma segura o nó e a outra perpassa a malha da rede em seus constantes laços.

Chamou-nos atenção o fato do artesão não perder o foco em sua atividade, ainda que estivéssemos conversando entre um nó e outro. As respostas para nossas perguntas não interferiam em seu fazer ligeiro. Embora seus ouvidos estivessem atentos à conversa que ali se desencadeava, seus olhos estavam sobre na rede em busca de buracos (rasgos) ou malhas repuxadas. Nos contaram que era necessário ter boa visão, pois um olhar impreciso deixaria "passar" os buracos, uma vez que as malhas em nylon de plástico exigem maior atenção por seu aspecto transparente ${ }^{11}$. Notamos que a agilidade nas mãos na realização do ofício é uma espécie de qualidade classificadora. Os profissionais mais ágeis, além de possuir mais clientes, desfrutam de um status $^{12}$ elevado socialmente reconhecido.

Antes da arte de remendar rede ter início, é necessário lavar a rede depois de retirada do mar, deixando-a "doce"13, isso para torna-la menos áspera e o nylon correr melhor ao serem dados os nós. O processo de remendo de rede tem início com a ação de "colher a rede", o que exige duas pessoas, cada uma colhendo a partir de uma das tralhas (ver imagem 5). Feito isso, o artesão escolhe uma das pontas da rede (a boia ou o chumbo) para pendurá-la e dar início ao remendo da rede (ver imagem 2). Curioso que as mulheres diferenciam os termos costurar e remendar. $\mathrm{O}$ ato de costurar designa a atividade ligada a roupa e remendar à rede de pesca. Após a rede pendurada, o artesão prepara suas ferramentas, amola a faca e "enche" as agulhas. O "encher" das agulhas muitas vezes é delegada aos demais membros da família, incluindo as crianças. Essa inclusão tornou-se mais forte a partir da fusão entre local de trabalho e casa. Costuma-se utilizar um balde para que o rolo de nylon não "corra” pelo chão (ver imagem 6).

\footnotetext{
${ }^{11}$ Para que o nylon aparecesse na fotografia foi necessário ampliar o contraste e a nitidez no momento da edição da imagem.

12 Não trata-se de status social, mas de um reconhecimento de estar entre os mais habilidosos e, por isso, respeitados e conhecidos entre o grupo e os pescadores da região.

${ }^{13}$ A retirada da salinidade é chamada dentre os pescadores e artesãos de "endoçar a rede".
} 

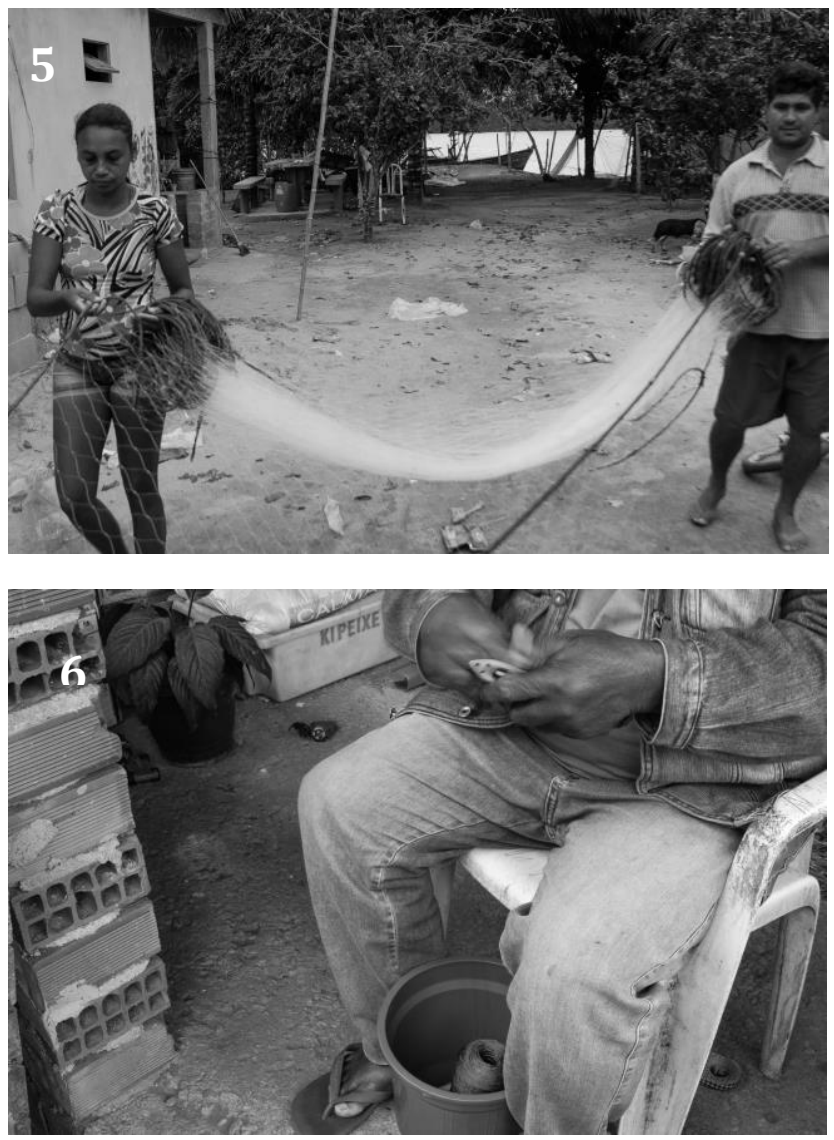

Imagens 5 e 6 - Colhendo a rede e enchendo agulha de pesca. Fotografias: Rochele Tenório Silva.

Realizado os preparativos anteriormente mencionados, o artesão dá início ao remendo da rede. A partir desse momento, poucas coisas serão capazes de retirar sua concentração e seus olhos de sobre a rede. A tarefa inicial é, a partir da ponta direita da rede, encontrar "rasgados" e "malhas corridas". A busca se dá esticando o pano com os dois braços (ver imagem 7). Por malhas corridas entendem as malhas que ao serem forçadas pelo peixe ou por alguma pedra acabam abrindo sem que o nylon se rompa, apenas tendo os nós "escorregado". Nesses casos a tarefa é retornar o nó para seu devido lugar, o que ocorre por meio de uma força no sentido contrário auxiliado por um pouco de saliva do artesão (ver imagem 8). A língua também é usada para identificar se a rede está devidamente "endoçada". Para essa tarefa, costuma-se utilizar uma luva ou um pedaço de câmara de ar de pneu enrolada na mão direita. 
Encontrado o buraco a ser remendado, esse é limpo e preparado (ver imagem 9). As pontas do nylon rompido não podem permanecer, pois se transformam em "pegas" (pontas que podem agarrar em outras partes da rede, podendo levá-las a ao "embolo" da rede). O remendo é feito a partir de um conjunto de voltas no nylon que forma um nó muito forte. Os nós têm local específico para ter início e fim, formando as malhas. Quando o buraco é muito grande, é usado o que eles chamam de "tacão", o qual se trata de um pedaço de outra rede que é usado como remendo.

Imagens 7, 8, 9 e 10 - Dos buracos ao remendo, passando pela correção de malhas corridas. Fotografia: Cristiano Bodart.
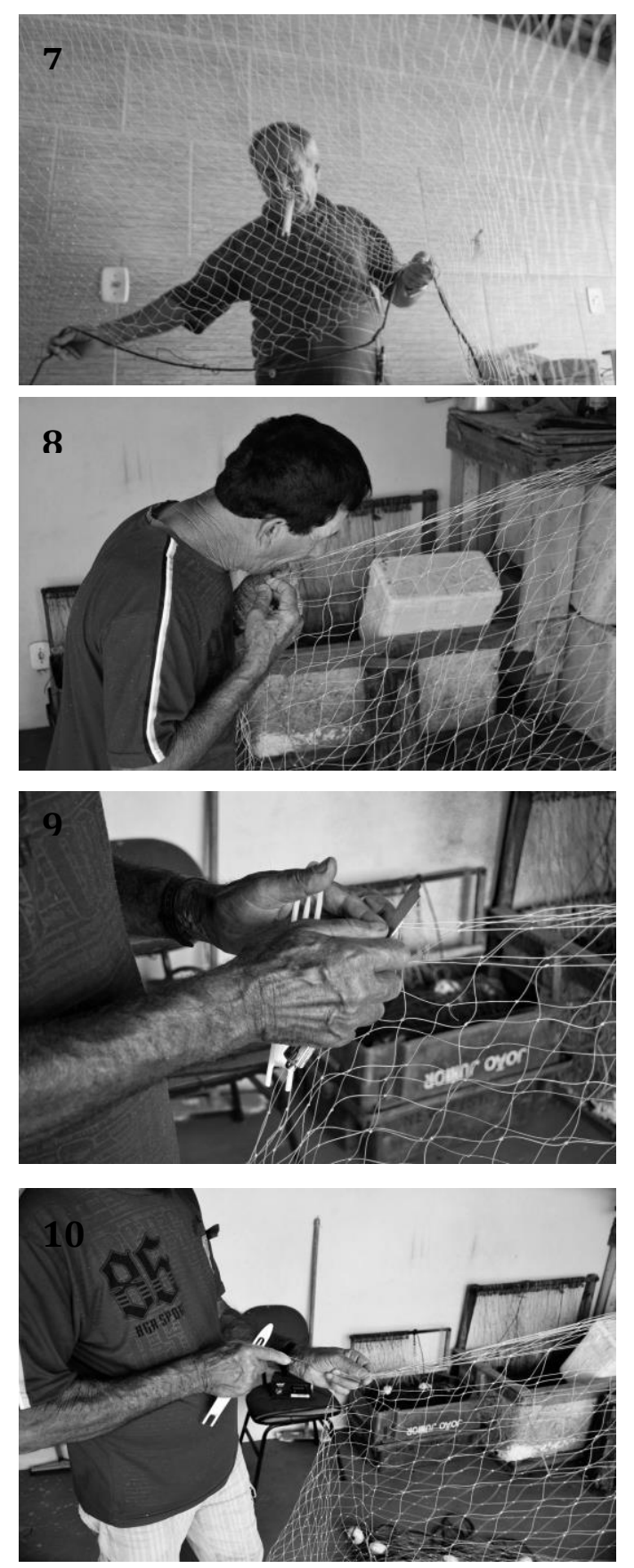
Os nós são executados com o auxílio de uma espécie de agulha de plástico produzida industrialmente para esse fim. No passado esta era confeccionada em bambu pelos próprios artesãos. Arguidos por que terem deixado de produzir as agulhas, nos contaram que tal agulha é relativamente barata (cerca de 10 reais) e que ela "nunca acaba, só de perder". "Eu tenho uma que uso há mais de 15 anos", nos confessou um dos artesãos.

A atividade é realizada de pé, sem a possibilidade de o artesão sentar ou se encostar para "descansar as pernas". "O trabalho é muito cansativo por ser feito em pé. Tenho um compadre que morreu de trombose. Eu mesmo vivo com dores nas varizes", relatou um dos artesãos entrevistados.

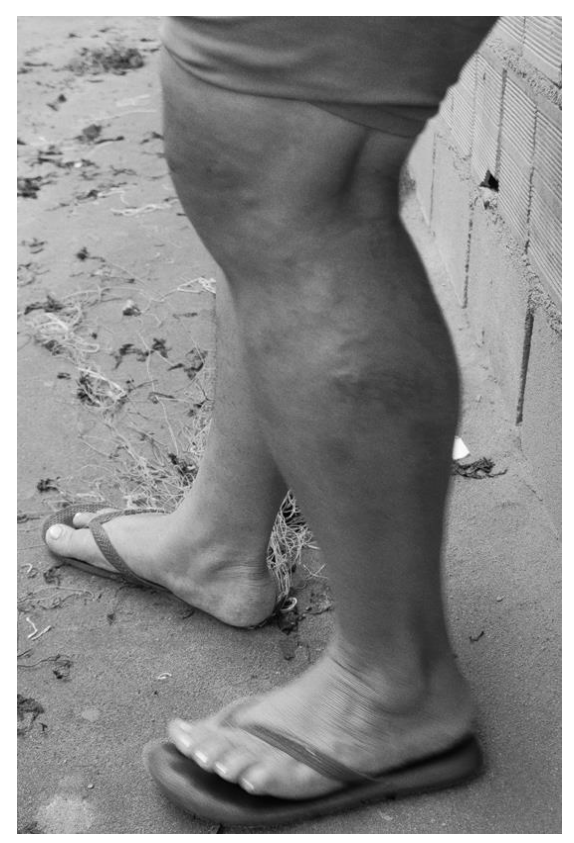

Imagem 11 - Marcas da atividade. Fotografia: Rochele Tenório Silva.

A reclamação de dores nas costas é recorrente, assim como o relato de dedos e mãos cortadas pelo nylon ou pela faca afiada. Perguntamos se eles se sentem só na realização da tarefa e se é um momento de reflexão. As respostas foram, em um aspecto, diferentes entre os homens e as mulheres. Enquanto as mulheres afirmam que realizam a atividade quase sempre com outra mulher, os homens a realizada solitariamente. 
Observamos, ainda que reconhecendo não sendo possível descrever a realidade como ela exatamente é (Novaes, 2008), e notamos que entre os homens o silêncio parece ser mais o costume da solidão do que a necessidade de atenção. Solidão causada pelo confinamento atual da atividade e pela escassez de outros profissionais que atuam no ofício. Uma das "mulheres do Pontal" afirmou que "trabalhar com companhia faz com que o tempo passe mais rápido e a conversa fica em dia". Por conversa em dia entendem o acesso ao conhecimento do que acontece no vilarejo, sejam questões coletivas ou de aspecto privada. Um dos artesãos, que há mais de 25 anos trabalha remendando redes, nos disse que hoje prefere trabalhar sozinho para não perder a concentração, isso por ter se habituado ao silêncio que outrora não havia. Segundo ele, a solidão não é percebida pela exigência de concentração no ofício.

Encontramos remendadores de rede de pesca ainda utilizando a rua (ver imagem 12).

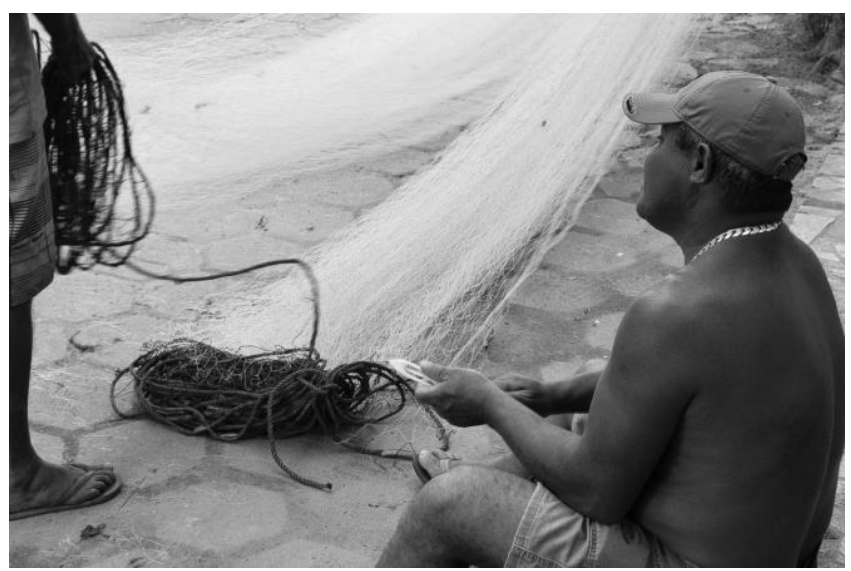

Imagem 12 - A solidariedade. Fotografia: Cristiano Bodart

Em contato com eles, descobrimos que eram pescadores que, pela falta de profissional que preste serviço de remendo de rede, acabam dividindo o tempo entre mar e rede. Como eles não são assalariados, não se importam de serem incomodados por quem passa na rua. Estando conversando com um desses pescadores, presenciamos algo que depois descobrimos ser muito comum: outro pescador se aproximou para "bater um papo" sobre a pescaria e foi, sem ser solicitado, pegando a agulha e enchendo com nylon enquanto ali conversava. Perguntado sobre seu ato, nos respondeu que a solidariedade entre os pescadores é uma característica que buscam preservar. Indagando outros pescadores sobre a suposta solidariedade, identificamos que a solidariedade é um elemento fundamental para a realização da atividade de pesca, pois esta se estende ao 
compartilhamento de informações sobre onde são encontrados os peixes naquela semana com mais facilidade, assim como a troca de favores e obediência as regras de boa convivência praticadas.

Durante nosso estudo de campo, não encontramos nenhum artesão fabricando rede. Buscando compreender a ausência dessa atividade, descobrimos que os pescadores têm optado por comprar o pano de rede em lojas por apresentar duas vantagens: i) o custo financeiro menor e; ii) por não precisar esperar semanas para estar pronta. Nas palavras de um dos pescadores entrevistado:

Uma rede de 100 metros e com 25 malhas de altura, se eu fosse pagar pra fazer me custaria uns 500 reais de mão-de-obra, além do nylon necessário. Isso só o pano. Eu comprando o pano pronto na loja, pago uns 150 reais. Depois eu pago o remendador para colocar a tralha, o que vai me sair por uns 60 contos. Em menos de três dias tenho minha rede prontinha para colocar n’água (sic).

A competição com a indústria fez com que tal tarefa praticamente desaparecesse, reduzindo o interesse pela atividade e, consequentemente, a não renovação de mão-deobra.

A atividade de colocar as tralhas que irão compor a boia e o chumba da rede é chamada de "entralhar". Chamou-nos a atenção a diferença do valor pago pela tarefa aos homens em relação às mulheres. No Pontal da Barra do Itapemirim essa diferença é ainda maior. Em Anchieta e Piúma, onde quase todos os artesãos são do sexo masculino (existindo apenas uma mulher que trabalha nesse ofício), enquanto é pago aos homens 60 reais para cada pano de 100 metros "entralhados", paga-se a artesã 50 reais pelo mesmo trabalho. No Pontal da Barra do Itapemirim, as mulheres (cerca de 100) recebem apenas 25 reais pelo mesmo trabalho, tarefa que leva cerca de 6 horas. Lá os poucos homens (menos de 15) que entralham ou remendam redes não são assalariados, trabalham apenas em suas próprias redes.

Todos os artesãos não possuem nenhuma cobertura trabalhista. Sua profissão não é regulamentada e não se configura nenhum vínculo empregatício com o dono da rede. Geralmente ao completar a idade de se aposentarem, buscam apoio nas Colônias de Pesca (espécie de associação de pescadores) para se aposentarem como pescadores (os homens) ou marisqueiras (as mulheres).

As "mulheres do Pontal" realizam o ofício de entralhar ou remendar redes no quintal de casa. Esse fato nos chamou a atenção por evidenciar o acúmulo de tarefa, 
uma vez que elas continuam ali realizando o papel de donas de casa e de mães (ver imagens 13 e 15).
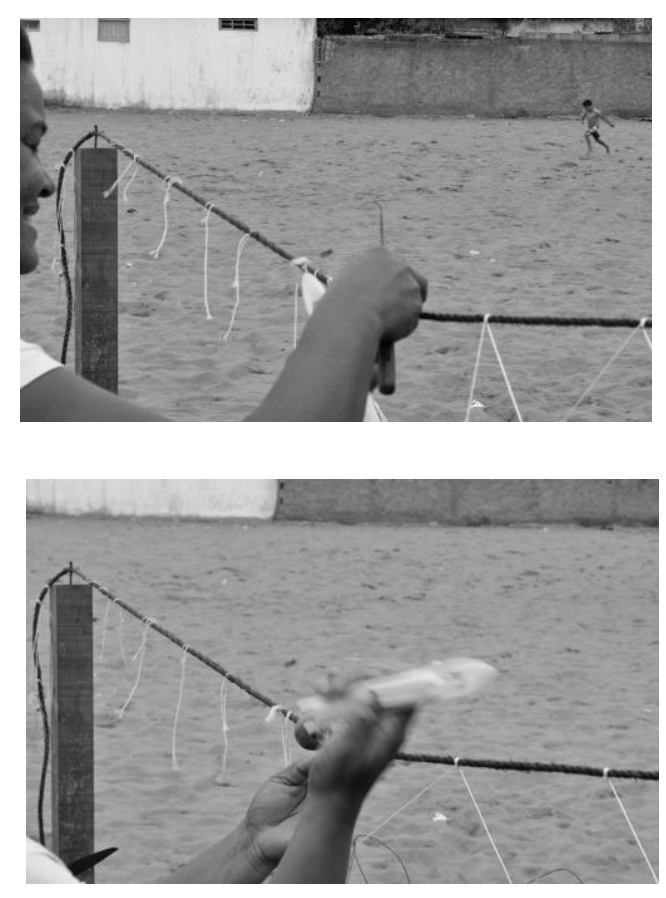

Imagens 13 e 14 - Entralhando a rede. Fotografias: Rochele Tenório da Silva.

Enquanto estão trabalhando nas redes, estão com os ouvidos atentos aos filhos que brincam ali próximo. Em muitos casos, a porta da cozinha está a alguns metros, pois não podem deixar de realizar as atividades "típicas das mulheres" do vilarejo. Enquanto remendam rede, ficam atentas ao sinal da panela de pressão e a crianças que perto correm.

A imagem 16 evidencia a fronteira que se mistura entre local de remendo de rede e o interior da casa.

No fim do dia, a parte da rede já remendada é amarrada a fim de delimitar o limite entre o que foi feito e o que há ainda a ser realizado no dia seguinte, tarefa que se inicia por volta das 7 horas da manhã e encerra entre as $17 \mathrm{~h}$ e $18 \mathrm{~h}$, dependendo do pôr do sol. À noite é momento de assistir Televisão e encher algumas agulhas com nylon para adiantar o trabalho do dia seguinte, sobretudo se o pagamento for por produtividade. 
Imagens 15 e 16: Fora de casa, mas nem tão fora assim. Fotografias: Rochele Tenório Silva.
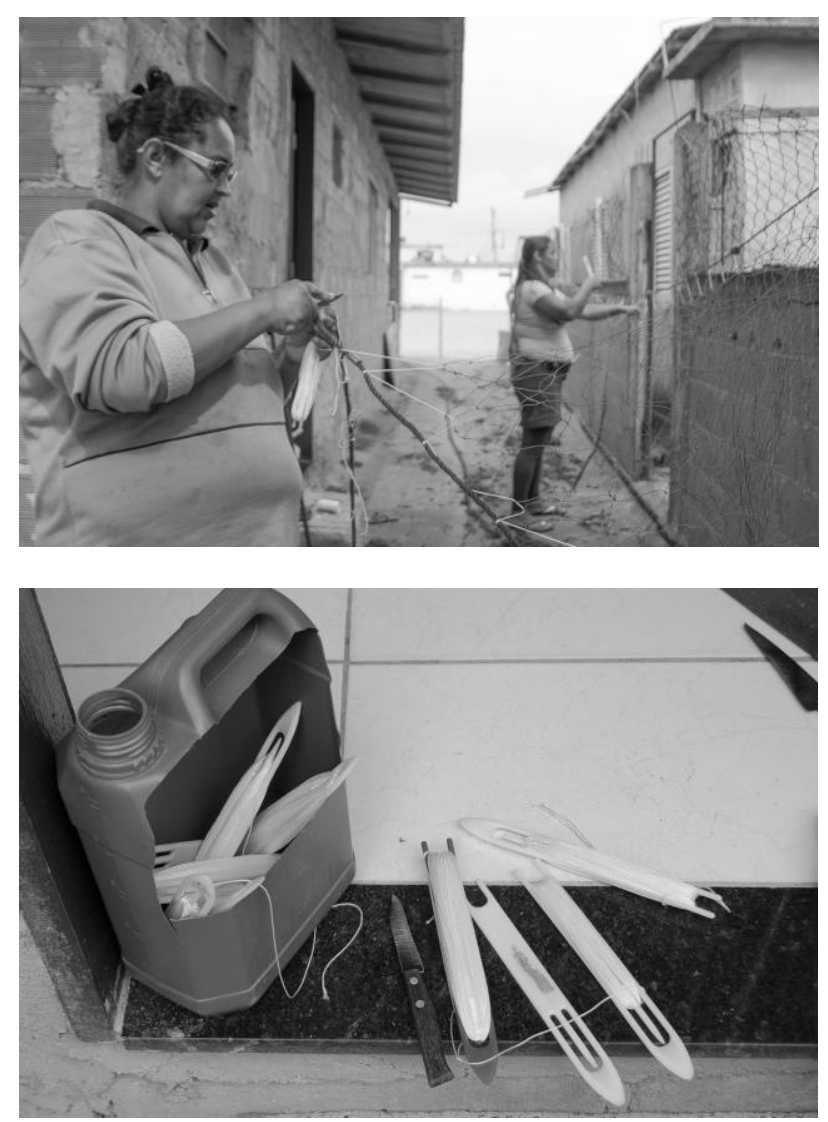

Após acompanhar e registrar atentamente a atividade desses profissionais, a etnografia chegava ao fim. O sentimento nesse instante foi de que no dia seguinte aquele ofício não fosse mais possível de ser observado, tamanha o volume de queixas das condições contrárias à sua realização ouvimos. Restou um último registro do artesão que recolhendo a rede concluída restava apenas a incerteza de que no dia seguinte estará ali, com sua agulha e faca. 


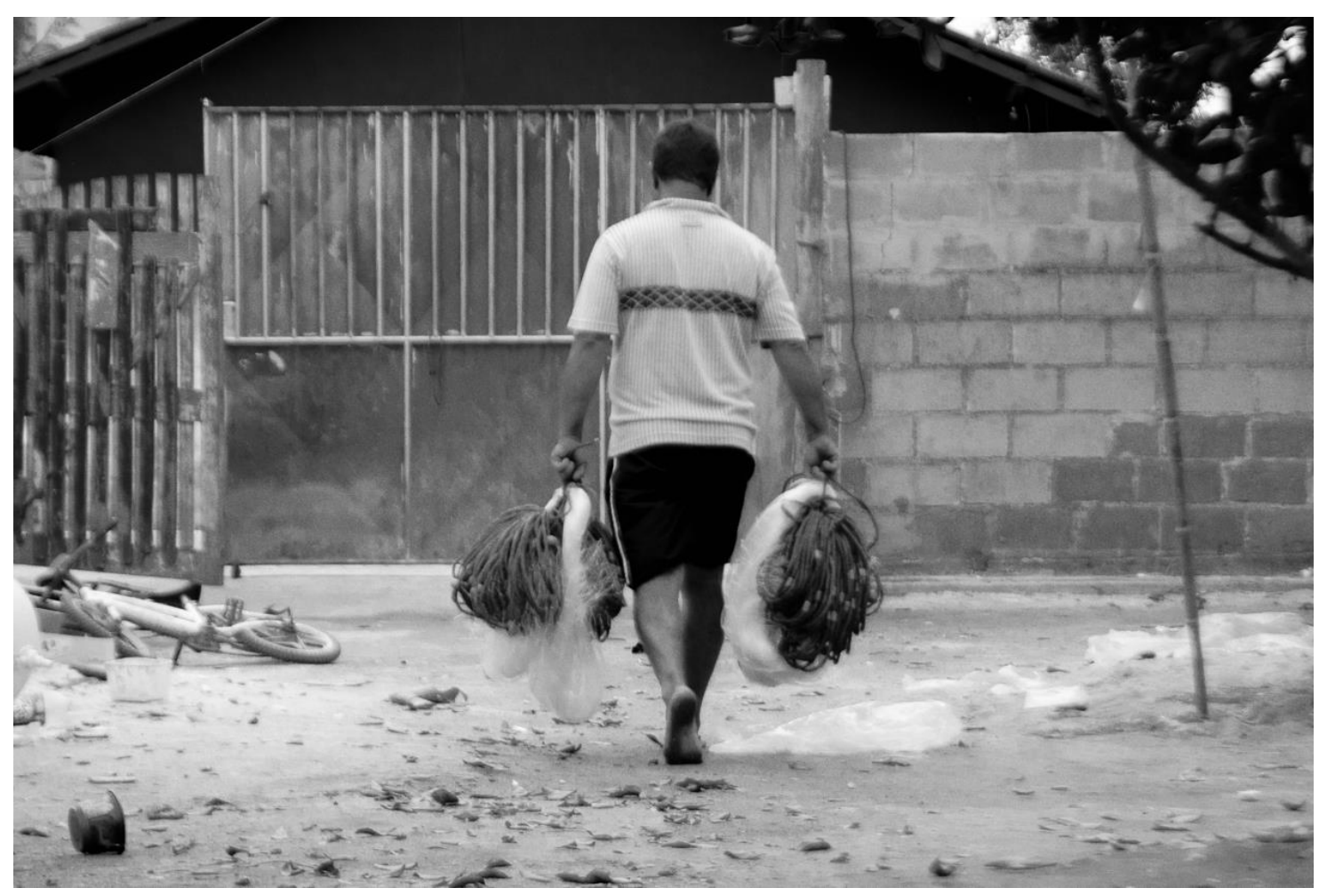

Imagem 17 - Findando o dia de trabalho. Fotografia: Rochele Tenório Silva.

\section{Considerações finais}

Realizar a descrição de uma atividade tradicional em risco de desaparecimento é sempre um trabalho gratificante, isso por compreendermos ser a etnografia uma técnica capaz de "registrar" atividades localizadas no tempo e no espaço, embora sendo a compreensão e interpretação desses "registros" variável, o que o enriquece ainda mais.

O tradicional recurso da narrativa textual foi de grande importância para compartilharmos "nossas interpretações", mas gostaríamos de ressaltar o potencial do recurso imagético. Este possibilita o leitor "imergir na cena" para além de nossas narrativas "emergindo interpretações" que muitas vezes não foram notadas pelos pesquisadores. Curioso que alguns detalhes nos passaram despercebidos durante as entrevistas in loco, os quais não foram registrados no tradicional diário de campo, mas identificados posteriormente a partir da observação dos registros fotográficos. Dito isto, acreditamos que ao integrar texto e imagem no processo descritivo, criamos condições 
para que o leitor seja ainda mais um analista enquanto realiza a leitura e a reflexão dos relatos aqui existentes de forma textual e imagético.

Notamos que o confinamento do ofício aos espaços fechados tem levado os artesãos, sobretudo do sexo masculino, a uma mudança em suas práticas sociais. Se antes a atividade era marcada pela publicidade e o compartilhamento do espaço de trabalho e de suas experiências diárias com outros artesãos, hoje a atividade se caracteriza pelo silêncio e atenção quase que exclusiva ao manuseio das ferramentas de ofício.

Embora não fosse o foco dessa pesquisa, ficou latente a desigualdade de gênero existente no ofício de remendador de rede. Igualmente, notamos que, assim como muitas outras atividades tradicionais, esta está forte e claramente ameaçada pela indústria. Em poucos anos, o pescador do sul do estado do Espírito Santo não terá esse profissional para recorrer, muito embora nos pareça que a pesca artesanal também tenha seus dias contados na região. Junto a eles desaparecerá a riqueza antropológica impregnada em sua atividade. A indústria já praticamente sucumbiu à atividade de fabricação de rede e o IBAMA, no Pontal da Barra do Itapemirim, parece colaborar para o processo de desaparecimento da arte do remendo, ofício já desconhecido pela maioria dos jovens da região. Nota-se a tendência das agulhas e facas deixarem, muito em breve, as mãos desses profissionais.

\section{Referências}

BERGER, Jonh. Modos de ver. Barcelona: Gustavo Gili, 2007.

BITTENCOURT, Luciana Aguiar. Algumas considerações sobre o uso da imagem fotográfica na pesquisa antropológica. In: FELDMAN-BIANCO, Bela; LEITE Míriam L. Moreira (orgs.). Desafios da Imagem: Fotografia, iconografia e vídeo nas ciências sociais. Campinas, SP: Papirus, 1998.

CHARTIER, Roger. A ordem dos livros: leitores, autores e bibliotecas na Europa entre os séculos XIV e XVIII. Trad. Mary Del Priore. Brasília: EdUnb, 1999.

CHARTIER, Roger. Introdução. Por uma sociologia histórica das práticas culturais. In:

A História Cultural entre práticas e representações. Col. Memória e sociedade. Trad. Maria Manuela Galhardo. Rio de Janeiro: Bertrand Brasil, 1990. 
DA MATTA, O ofício do etnólogo, ou como ter "antropological blues". In: NUNES, Edson de Oliveira. A aventura sociológica: objetividade, paixão, improviso e método na pesquisa social. Rio de Janeiro: Zahar Editores, 1978, p. 23-35

GEERTZ, Clifford. A interpretação das culturas. Rio de Janeiro: LTC, 1989.

KOSSOY, Boris. Fotografia \& História. São Paulo: Ateliê Editorial, 2001.

MERLEAU-PONTY, Maurice. O cinema e a nova psicologia. In: Ismail Xavier (org.). A experiência do cinema, antologia. Coleção Arte e Cultura, v. 5. Rio de Janeiro: Graal/ Embrafilme. 1983. pp.103-117.

NOVAES, Sylvia Caiuby. A construção de imagens na pesquisa de campo em antropologia. In: Iluminuras, Porto Alegre, v.13, n.31, p.11-29, jul./dez. 2012. Disponível em:< http://seer.ufrgs.br/index.php/iluminuras/article/view/36791/23802> Acessado em: 20 ago. 2014.

NOVAES, Sylvia Caiuby. Imagem, magia e imaginação: desafios ao texto antropológico. In: Mana, v.14, n², p. 455-475, 2008.

Disponível em: $<$ http://www.scielo.br/pdf/mana/v14n2/a07v14n2.pdf $>$ Acessado em: 22 ago. 2014.

PEIXOTO, Clarice Ehlers. Caleidoscópio de imagens: o uso do vídeo e a sua contribuição à análise das relações sociais. In: FELDMAN-BIANCO, Bela; LEITE Míriam L. Moreira (orgs.). Desafios da Imagem: Fotografia, iconografia e vídeo nas ciências sociais. Campinas, SP: Papirus, 1998.

ROCHA, E. P. Q.; BARROS, C.; PEREIRA, C. Perspectivas do método etnográfico em marketing: consumo, comunicação e netnografia. In: ENANPAD, 2005, Brasília (DF). Anais...Brasília: ANPAD, 2005.

VELHO, Gilberto. Observando o familiar. In: NUNES, Edson de Oliveira. A aventura sociológica: objetividade, paixão, improviso e método na pesquisa social. Rio de Janeiro: Zahar Editores, 1978, p. 36-46.

Recebido em: 15/09/2014

Aprovado em: 30/11/2014 